\title{
Improved Abundance Sensitivity of Molecular Ions in Positive-Ion APCI MS Analysis of Petroleum in Toluene
}

\author{
Young Hwan Kim ${ }^{\mathrm{a}}$ and Sunghwan $\mathrm{Kim}^{\mathrm{b}}$ \\ ${ }^{a}$ Korea Basic Science Institute, Mass Spectrometry Team, Ochang, Republic of Korea \\ ${ }^{\mathrm{b}}$ Kyungpook National University, Department of Chemistry, Daegu, Republic of Korea
}

Positive-ion atmospheric pressure chemical ionization (APCI) Fourier transform ion cyclotron resonance mass spectrometry (FT-ICR MS) analyses of petroleum sample were performed with higher sensitivity by switching the solvent composition from toluene and methanol or acetonitrile to a one-component system consisting only of toluene. In solvent blends, molecular ions were more abundant than were protonated ions with increasing percentages of toluene. In $100 \%$ toluene, the double-bond equivalence (DBE) distributions of molecular ions obtained by APCI MS for each compound class were very similar to those obtained in dopant assisted atmospheric pressure photo ionization (APPI) MS analyses. Therefore, it was concluded that charge-transfer reaction, which is important in toluene-doped APPI processes, also plays a major role in positive-ion APCI. In the DBE distributions of $\mathrm{S}_{1}, \mathrm{~S}_{2}$, and SO heteroatom classes, a larger enhancement in the relative abundance of molecular ions at fairly specific DBE values was observed as the solvent was progressively switched to toluene. This enhanced abundance of molecular ions was likely dependent on molecular structure. (J Am Soc Mass Spectrom 2010, 21, 386-392) (c) 2010 American Society for Mass Spectrometry

$\mathrm{D}$ ue to the complexity of petroleum samples, determining their chemical composition represents a great challenge. Thus far, Fourier transform ion cyclotron resonance mass spectrometry (FTICR MS) is the only tool that can resolve the complex petroleum matrix. FT-ICR MS routinely achieves a mass resolving power $\left(\mathrm{m} / \Delta \mathrm{m}_{50 \%}\right)>400,000\left(\Delta \mathrm{m}_{50 \%}\right.$ represents the magnitude-mode, FT-ICR mass spectral peak full width at half-maximum peak height), and a $\mathrm{m} / \Delta \mathrm{m}_{50 \%}=3300,000$ has been reported for a $\sim 1 \mathrm{kDa}$ peptide [1]. Additionally, for a well-resolved peak, FT-ICR MS can provide a mass accuracy $(<400 \mathrm{ppb}$ rms error) such that elemental composition may be uniquely assigned [2]. The molecular composition may then be sorted by various tools, including Kendrick mass defect versus Kendrick mass [3] or van Krevelen analyses, e.g., $\mathrm{H} / \mathrm{C}$ ratio versus the $\mathrm{O} / \mathrm{C}$ or $\mathrm{N} / \mathrm{C}$ or $\mathrm{S} / \mathrm{C}$ ratios [4]. The double-bond equivalents and carbon number distribution obtained from the elemental compositions can be plotted as iso-abundance contoured plots to sort molecular compositions for particular heteroatom classes. The successful application of FT-ICR MS to study chemical compositions of petroleum at the molecular level, i.e., petroleomics, is therefore not surprising [5-7].

Address reprint requests to Dr. S. Kim, Department of Chemistry, Kyungpook National University, Daegu, Republic of Korea. E-mail: sunghwank@ knu.ac.kr
Even with the great resolving power and mass accuracy of FT-ICR MS, chemical components can only be studied if they are ionized, which makes the ionization technique one of the key parameters in any mass spectrometry analysis. This importance is emphasized in petroleomics because petroleum is composed of a wide variety of chemical components ranging from hydrocarbons to polar compounds. Unfortunately, single-ionization techniques are usually fairly specific in the types of molecules they can ionize, and no single technique can be applied to the entire chemical composition of petroleum. Therefore, to generate an accurate picture of petroleum composition, combination of right ionization techniques must be utilized. From the beginning of petroleomics, electrospray ionization (ESI) has been used primarily to study the polar components of petroleum $[5,8,9]$, whereas the nonpolar hydrocarbon constituents have been studied with field desorption (FD) techniques [10]. Recently, atmospheric pressure photo ionization (APPI) [11] and atmospheric pressure laser ionization (APLI) [12-14] have gained popularity in the petroleomic analyses because they ionize a wide range of molecules, such as aromatic hydrocarbons and sulfur-containing compounds. Atmospheric pressure chemical ionization (APCI) is another technique that has been used for petroleomic analyses $[15,16]$. However, the application of APCI in petroleomics has been limited so far, presumably due to its sensitivity compared with ESI [16]. 
In the current study, the sensitivity of positive-ion APCI FT-ICR MS was enhanced by changing the solvent composition. This result corroborates results of a previous study [17] in which higher sensitivity was achieved in APCI MS analyses of standard polyaromatic hydrocarbons (PAHs) in a toluene solvent.

\section{Experimental}

HPLC grade methanol, toluene, and acetonitrile were purchased from Merck (Gibbstown, NJ, USA) and used without further purification. A bitumen oil sample was dissolved to $2 \mathrm{mg} / \mathrm{mL}$ toluene as a stock solution. Before analysis, samples were prepared by diluting the stock solution to $1 \mathrm{mg} / \mathrm{mL}$ with solvent compositions of toluene:methanol (50:50 vol/vol), toluene:methanol $(75: 25 \mathrm{vol} / \mathrm{vol})$, toluene:acetonitrile (50:50 vol/vol), or toluene $(100 \%)$. Prepared samples were directly injected with a syringe pump (Harvard, Holliston, MA, USA) at a flow rate of $10 \mu \mathrm{L} / \mathrm{min}$. Flow rate of the analyses was kept at the minimum value to prevent source contamination. Analyses were performed with a 15 T FT-ICR mass spectrometer at the Korean Basic Science Institute (KBSI, Ochang-eup, Korea). The Apex hybrid Qq-FT instrument is equipped with Bruker Apollo II dual source. APCI and APPI sources were obtained from Bruker Daltonics (Billerica, MA, USA). Nitrogen was used as the drying and nebulizing gas in both ionization sources. The operating parameters for APCI analyses were corona needle current $2500 \mathrm{nA}$, nebulizing temperature $190{ }^{\circ} \mathrm{C}$ with $3.0 \mathrm{~L} / \mathrm{min}$ flow rate, and drying gas temperature $200{ }^{\circ} \mathrm{C}$ with $2.0 \mathrm{~L} / \mathrm{min}$ flow rate, and the skimmer voltage was set to $13.0 \mathrm{~V}$ to minimize in-source fragmentation. The operating parameters for APPI analyses were the same as those used for APCI. Ionized samples were accumulated in the collision cell for $1 \mathrm{~s}$ and transferred to the ICR cell with a $2 \mathrm{~ms}$ time-of-flight window. Argon gas was used in the collision cell. Both sidekick and gated trapping approaches were utilized. A sidekick voltage of $20 \mathrm{~V}$ was used to initially trap the ions. After transferring the ions to the ICR trap, the trap voltage was raised to $3 \mathrm{~V}$ and ramped down to $1.5 \mathrm{~V}$ for detection. A total of $2 \times 10^{6}$ data points were obtained within about $1 \mathrm{~s}$. For each spectrum, 100 scans were accumulated to increase the signal-to-noise ratio. The resulting time-domain signal was zero-filled and apodized with a sine bell function before FFT. The obtained spectrum was processed with ChemBrowser software version 1.0 (BNF Technology, Daejeon, Korea).

\section{Results and Discussion}

\section{Comparisons of Signal Abundance and Molecular Class Distribution}

The noise levels of all APCI FT-ICR MS spectra were nearly identical. Therefore, the observed ion abundance was equivalent to the signal-to-noise $(\mathrm{S} / \mathrm{N})$ ratio. Over- all, S/N increased as $100 \%$ toluene (Figure 1a) > toluene/methanol 75:25 (refer to Supplementary data, which can be found in the electronic version of this article) $>$ toluene/methanol 50:50 (Figure 1b) and toluene/ACN 50:50 (refer to Supplementary data). This result is consistent with a previous report by Herrera et al. [17], in which standard analyses of PAHs exhibited higher relative ionization efficiency and sensitivity when toluene was used as the solvent rather than ACN or $\mathrm{MeOH}$. In addition, the use of $\mathrm{ACN}$ as the solvent resulted in an order of magnitude better sensitivity than did use of $\mathrm{MeOH}$. However, in the current study, the spectra obtained with toluene/methanol 50:50 (Figure 1b) and toluene/ACN 50:50 (refer to Supplementary data) were almost identical.

Molecular formulae of the general form $\mathrm{C}_{\mathrm{c}} \mathrm{H}_{\mathrm{h}} \mathrm{N}_{n} \mathrm{O}_{\mathrm{o}} \mathrm{S}_{\mathrm{s}}$ were assigned to spectral peaks with no limit set on the amounts of $\mathrm{c}$ and $\mathrm{h}$. and the following limits were imposed on the remaining elements: $0 \leq n \leq 5,0 \leq 0 \leq$ $10,0 \leq s \leq 2$. Both protonated $[\mathrm{M}+\mathrm{H}]^{+}$and molecular positive ions (or radicals), $\mathrm{M}^{+}$, were taken into consideration because typical APCI processes simultaneously yield both species. Table 1 shows that the class distribution of spectra obtained from samples prepared with 100 and 75\% toluene have a higher percentage of hydrocarbon (HC) compared with samples prepared in $50 \%$ toluene. The relative $\mathrm{HC}$ abundance decreased from $19.2 \%$ to $11.9 \%$ as the percent of toluene decreased from $100 \%$ to $50 \%$.

\section{APCI and APPI Data and the Importance of Charge-Transfer Reaction}

Double-bond equivalences $(\mathrm{DBE}=$ number of rings plus double bonds to carbon) of protonated and molecular $\mathrm{HC}$ ions were calculated from chemical formulae by the following equation:

$$
D B E=c-h / 2+n / 2+1
$$

(for the neutral molecule, $\mathrm{C}_{c} \mathrm{H}_{h} \mathrm{~N}_{n} \mathrm{O}_{o} \mathrm{~S}_{s}$ )

The resulting DBE distributions were plotted and are shown in Figure 2. The relative abundance of molecular ions was similar to that of protonated ions using the $50 \%$ toluene/MeOH solvent blend, as indicated in Figure 2a. The same result was observed with the $50 \%$ toluene/ACN blend (not shown). However, in the APCI analyses of petroleum, the relative abundance of molecular ions was greatly enhanced over that of protonated ions with increasing proportions of toluene (Figure 2c and $\mathrm{d}$ ). The relatively greater abundance of molecular ions is one of the primary reasons for the enhanced sensitivity observed in Figure 1.

The increased abundance of molecular ions observed with increasing toluene content suggests that in the APCI process, the toluene can play a key role in the formation of the molecular ion. One likely mechanism for molecular ion formation is a charge-transfer reaction between the toluene radical and neutral compounds 
(a)

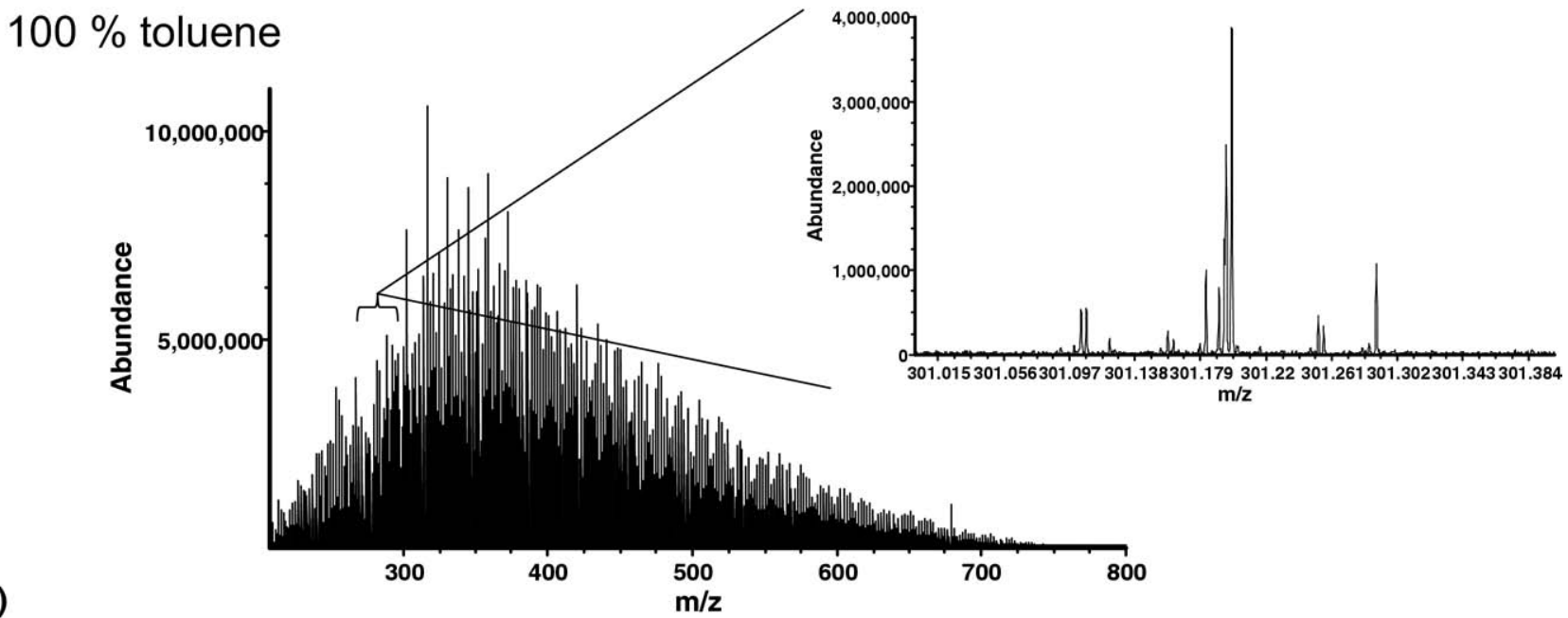

\section{toluene/MeOH 50:50}

(b)

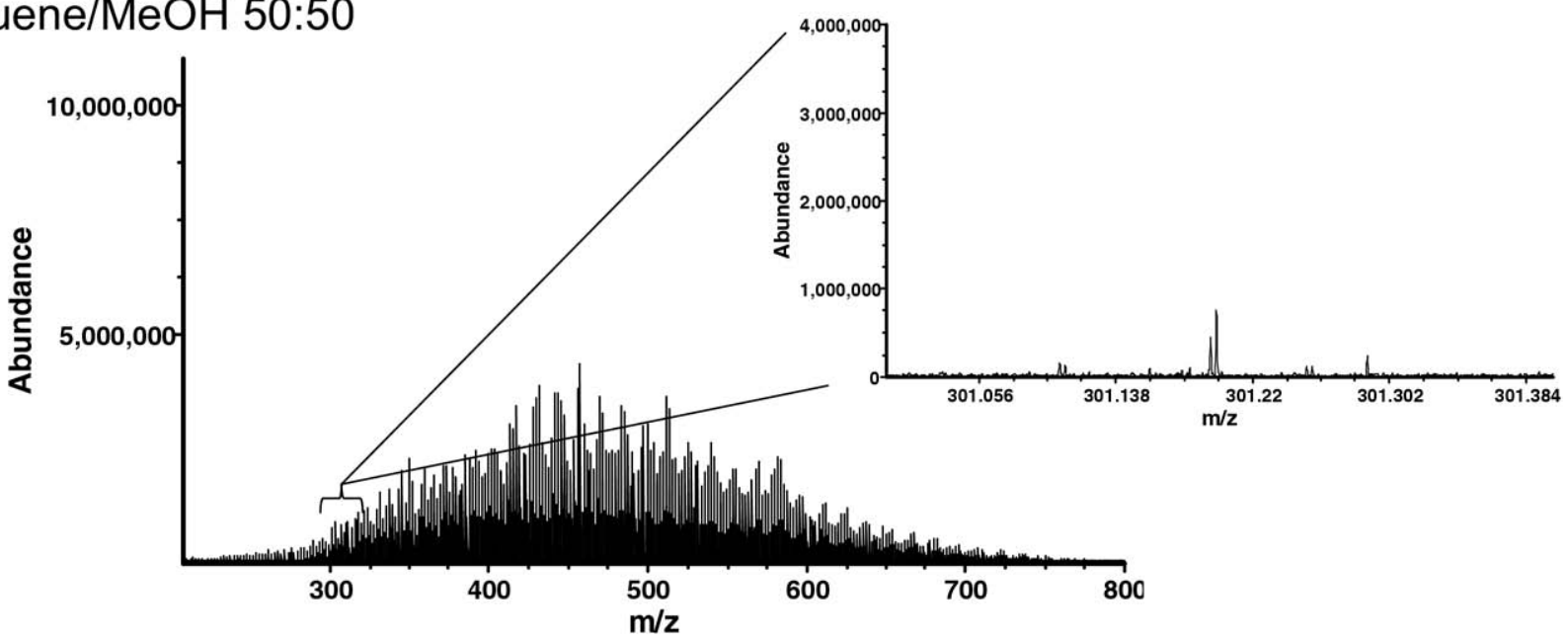

Figure 1. Effect of solvent compositions on APCI MS sensitivity for petroleum.

(refer to Reaction 1). The solvent radical ions can be generated by reactions with either $\mathrm{N}_{2}^{+\cdot}$ or $\mathrm{N}_{4}^{+}[18,19]$ in the APCI source. In fact, benzene, which has an aromatic structure similar to that of toluene, has been used as a charge-transfer agent in chemical ionization $[20,21]$.

$$
M^{+\cdot}+A \rightarrow M+A^{+}
$$

(M: solvent such as toluene or methanol, A: analyte).

Table 1. Major heteroatom class distributions observed in Figure 1

\begin{tabular}{lccr}
\hline & Toluene (100) & $\begin{array}{c}\text { Tol: } \mathrm{MeOH} \\
(75: 25)\end{array}$ & $\begin{array}{c}\text { Tol: } \mathrm{MeOH} \\
(50: 50)\end{array}$ \\
\hline \hline $\mathrm{S}_{1}$ & $31.1 \%( \pm 0.8)$ & $30.7 \%( \pm 0.5)$ & $33.4 \%( \pm 0.4)$ \\
$\mathrm{HC}$ & $19.2 \%( \pm 0.1)$ & $15.8 \%( \pm 0.1)$ & $11.9 \%( \pm 0.3)$ \\
$\mathrm{S}_{2}$ & $9.4 \%( \pm 0.2)$ & $10.3 \%( \pm 0.2)$ & $11.8 \%( \pm 0.1)$ \\
$\mathrm{N}_{1}$ & $7.6 \%( \pm 0.5)$ & $9.6 \%( \pm 0.4)$ & $9.6 \%( \pm 0.5)$ \\
$\mathrm{O}_{1} \mathrm{~S}_{1}$ & $3.6 \%( \pm 0.1)$ & $4.2 \%( \pm 0.1)$ & $4.8 \%( \pm 0.2)$ \\
$\mathrm{O}_{1}$ & $3.4 \%( \pm 0.1)$ & $3.2 \%( \pm 0.1)$ & $2.7 \%( \pm 0.1)$ \\
$\mathrm{N}_{1} \mathrm{O}_{1}$ & $2.3 \%( \pm 0.1)$ & $2.8 \%( \pm 0.1)$ & $2.4 \%( \pm 0.1)$ \\
$\mathrm{N}_{1} \mathrm{~S}_{1}$ & $1.4 \%( \pm 0.3)$ & $1.6 \%( \pm 0.1)$ & $1.4 \%( \pm 0.1)$ \\
\hline
\end{tabular}

Herrera and coworkers [17] also observed increased sensitivity using toluene and suggested that the chargetransfer reaction by the toluene radical cation could be important. To demonstrate experimentally the importance of this charge-transfer reaction in APCI analyses, the same sample was analyzed by dopant assisted atmospheric pressure photo ionization (APPI). The dopant assisted APPI has been used to increase ionization efficiency overall for compounds [22]. The process generates molecular radical ions either by means of a charge-transfer reaction or by proton transfer [23]. Toluene is widely used as a dopant in APPI analyses, and the toluene radicals generated by the following reaction play a major role during the ionization process $[23,24]$.

$$
\mathrm{C}_{7} \mathrm{H}_{8}+10 \mathrm{eV} \text { photon } \rightarrow \mathrm{C}_{7} \mathrm{H}_{8}^{+\cdot}+e^{-}
$$

A positive-ion APPI mass spectrum of the same petroleum sample dissolved in 50\% toluene/methanol was compared with the corresponding APCI mass spectrum. The APPI DBE distribution of HCs is displayed in Figure $2 \mathrm{~d}$. The molecular radical ions produced by the 


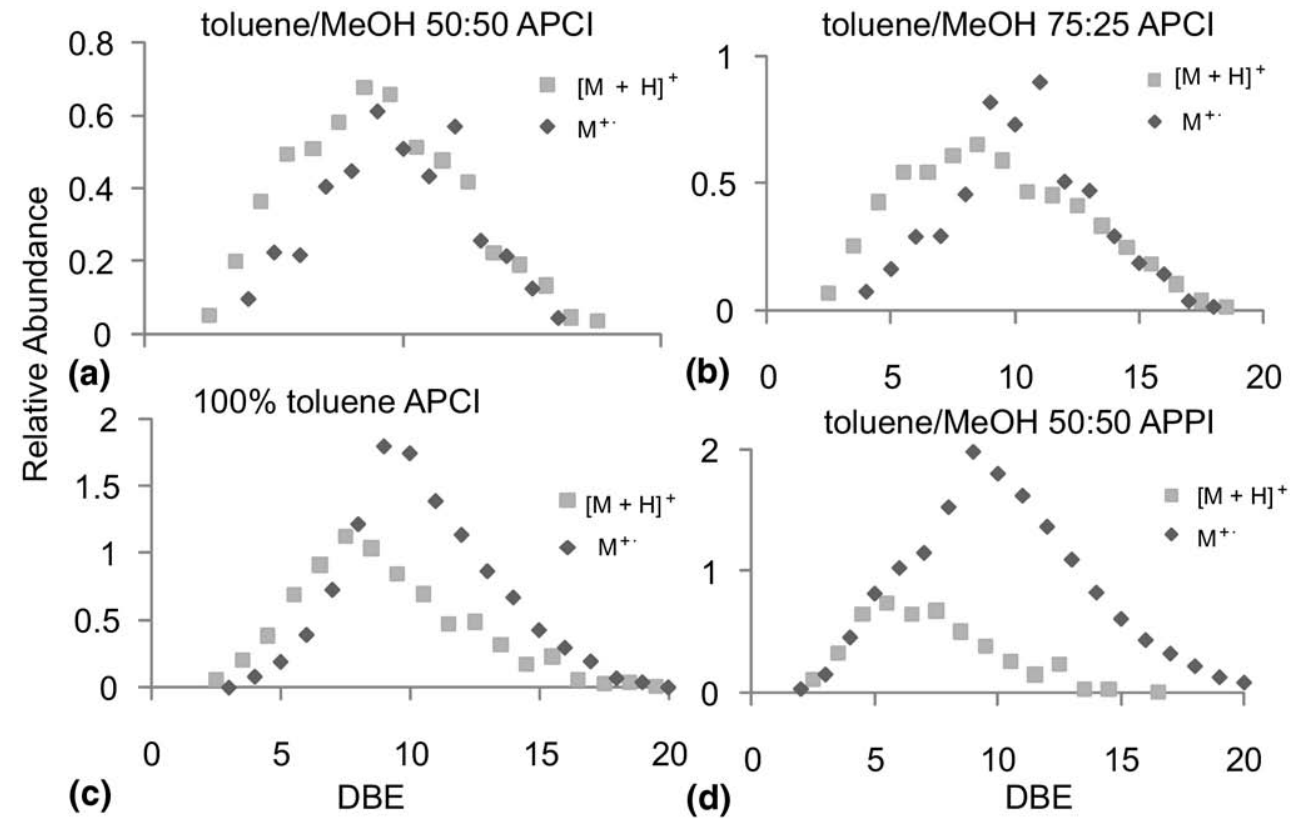

Figure 2. DBE distributions of protonated and molecular ions of hydrocarbon compounds.

APPI process were more dominant than were those produced by APCI, and the DBE distribution was similar to that obtained for samples dissolved in $100 \%$ toluene, as shown in Figure $2 \mathrm{c}$ and $\mathrm{d}$. The APCI mass spectra became more similar to those obtained by APPI as the content of toluene in the solvent was increased. Figure 3 shows a similar effect with $S_{1}$ compounds. The comparison between APCI and APPI data can be extended to other ion classes $\left(S_{2}\right.$ and $S O$ ) with similar trends (Figures 4 and 5). This comparison shows that molecular ions are generated by the similar ion/ molecular reactions for both ionization processes regardless difference in the initial ion formation processes. Therefore, the charge-transfer reaction by the toluene radical plays a major role in the formation of molecular ions when neat toluene is used as the solvent in positive-mode APCI analyses.

Significant amount of protonated compounds were also observed for the basic compounds (e.g., $\mathrm{N}_{1}$ class compounds, data not shown). To investigate the role

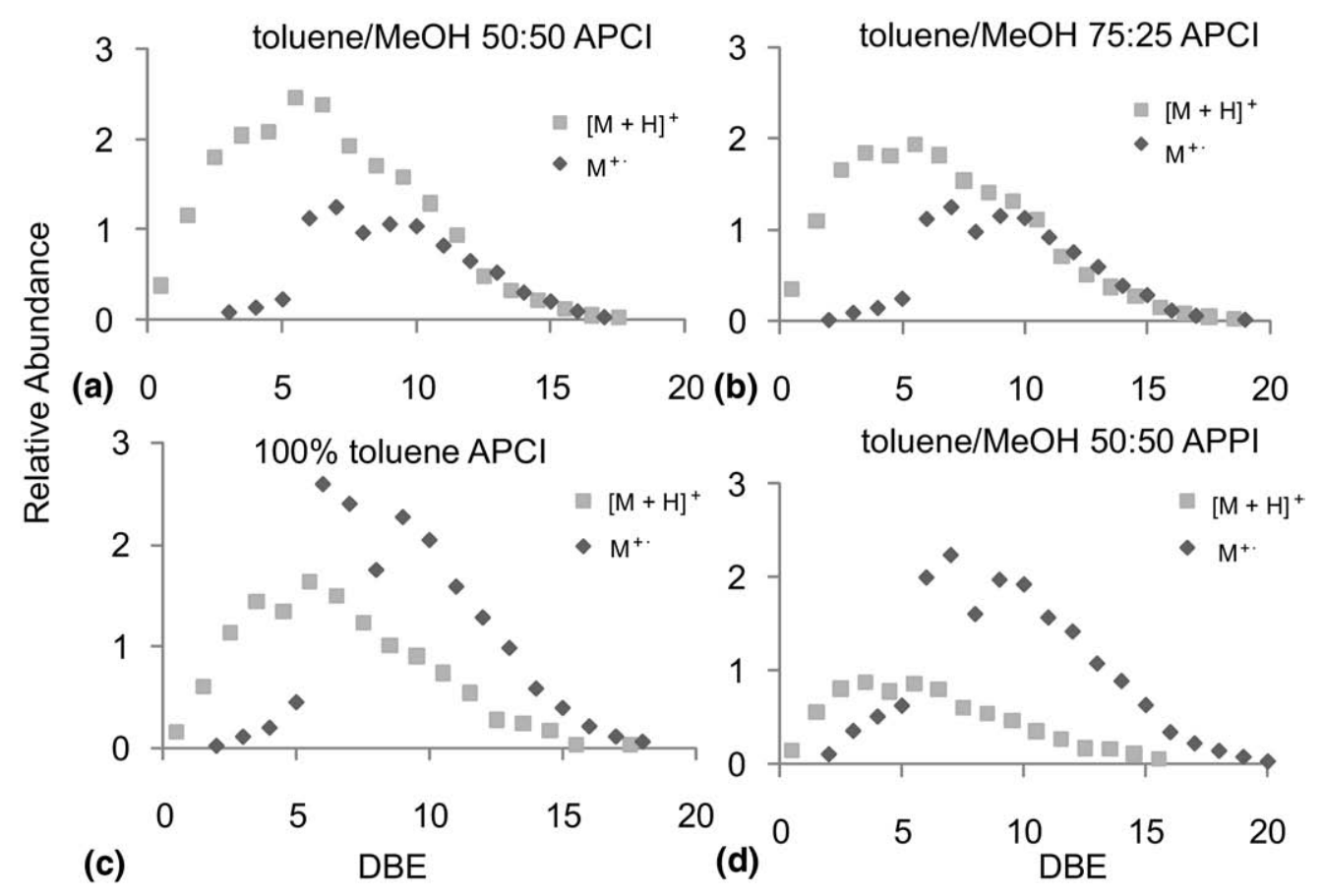

Figure 3. DBE distributions of protonated and molecular ions of $S_{1}$ compounds. 

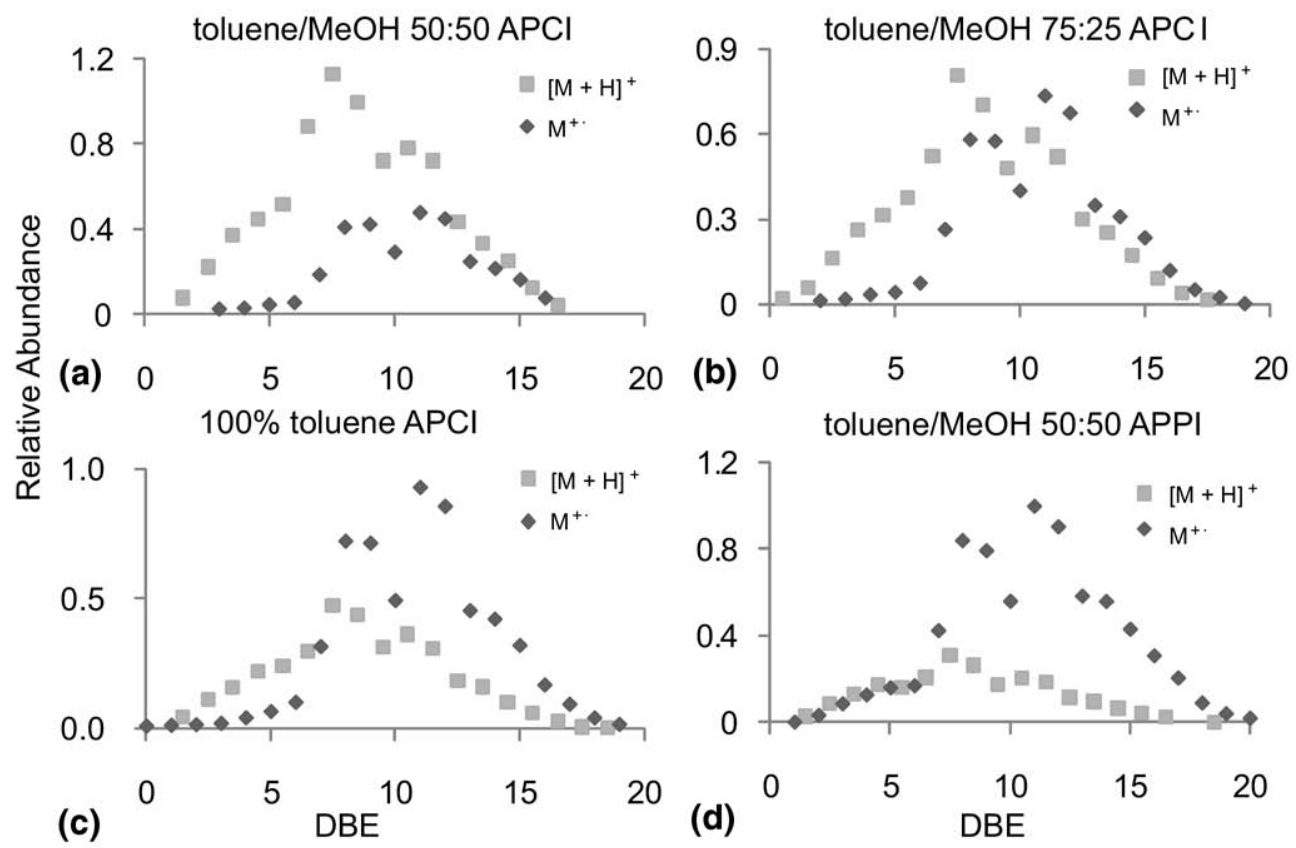

Figure 4. DBE distributions of protonated and molecular ions of $\mathrm{S}_{2}$ compounds.

of toluene in the proton transfer reaction, acridine $\left(\mathrm{C}_{13} \mathrm{H}_{9} \mathrm{~N}\right)$ was dissolved into deuterated toluene $\left(\mathrm{C}_{7} \mathrm{D}_{8}\right)$ solvent and analyzed by positive mode APCI. Acridine was chosen since it was the polyaromatic basic compound. It was observed that majority of ions were found to be $[\mathrm{M}+\mathrm{H}]^{+}$instead of $[\mathrm{M}+\mathrm{D}]^{+}$(Table 2). This data suggested that toluene plays a minor role as a source of proton in the ionization process, and it raises a question on where the protons came from. The proton might have originated from hydrogen exchange reaction between analytes. However, Herrera et al. did thermodynamic calculation and concluded that it was less likely that the hydrogen exchange reactions occurred [17]. Further study is being conducted to find the source of proton in the process.

Overall, the results obtained in this study corroborate results of a previous study [25] in which both charge exchange and proton transfer were found to be

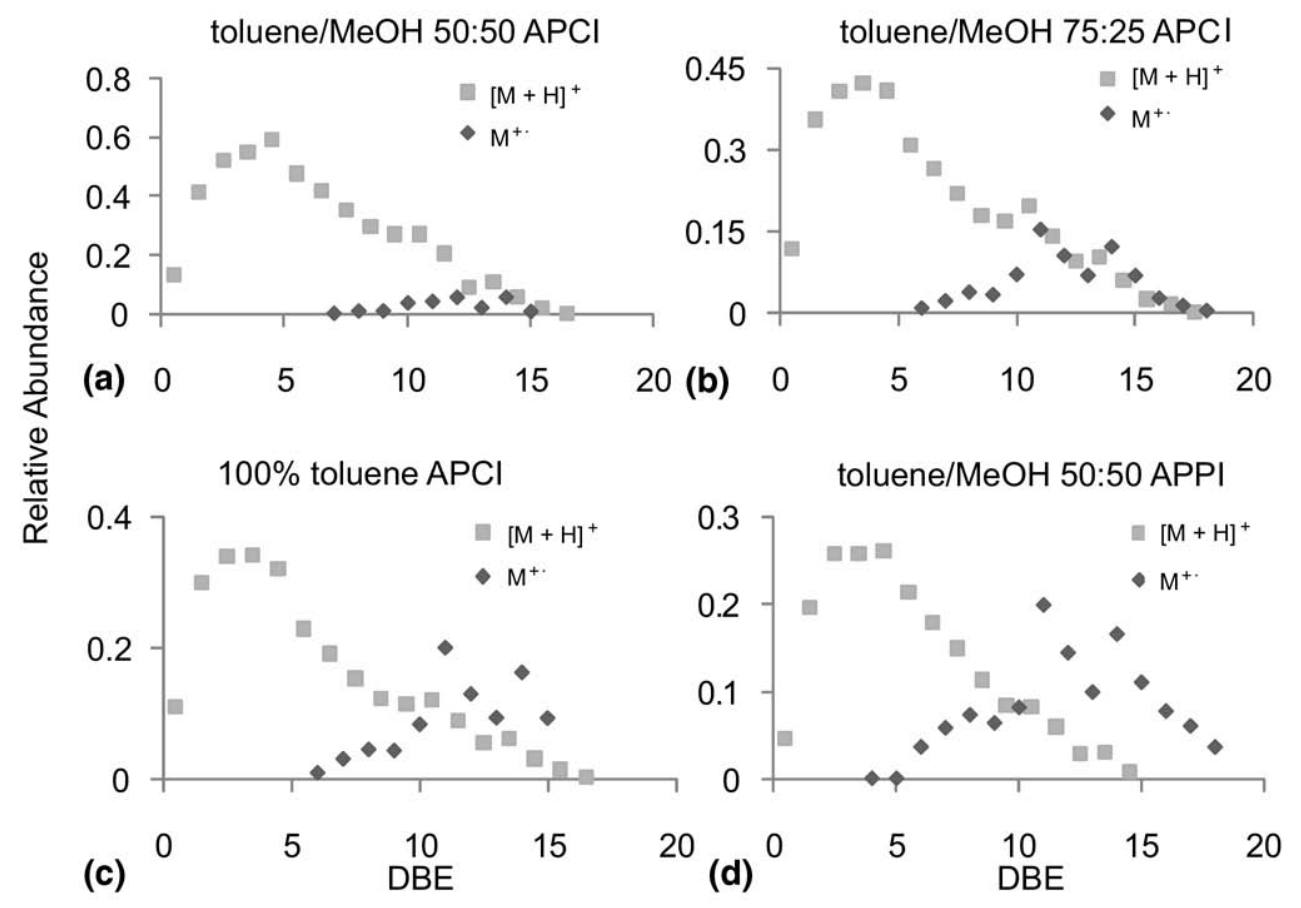

Figure 5. DBE distributions of protonated and molecular ions of SO compounds. 
Table 2. Peaks observed by (+) APCI analysis of acridine $\left(\mathrm{C}_{13} \mathrm{H}_{9} \mathrm{~N}\right)$ dissolved in deuterated toluene $\left(\mathrm{C}_{7} \mathrm{D}_{8}\right)$

\begin{tabular}{lc}
\hline Observed ions & Relative abundance \\
\hline \hline $\mathrm{C}_{13} \mathrm{H}_{9} \mathrm{~N}^{+\cdot}$ & $12.1 \%( \pm 1.3)$ \\
{$\left[\mathrm{C}_{13} \mathrm{H}_{9} \mathrm{~N}+\mathrm{H}\right]^{+}$} & $100 \%$ \\
{$\left[\mathrm{C}_{12} \mathrm{H}_{9} \mathrm{~N}+{ }^{13} \mathrm{C}\right]^{+}$} & $15.4 \%( \pm 1.4)$ \\
{$\left[\mathrm{C}_{13} \mathrm{H}_{9} \mathrm{~N}+\mathrm{D}\right]^{+}$} & $5.9 \%( \pm 0.0)$ \\
\hline
\end{tabular}

important for APCI of hydrocarbon molecules. In addition, it must be emphasized that a similar conclusion was drawn by two independent studies, the current and previous study [25], where different instruments and source geometries were used. This shows that the proposed importance of charge-transfer reaction in APCI is not instrument- or source geometry-dependent.

\section{Enhancement of Molecular Ions Containing Sulfur Atoms}

Figure 3 shows that the abundance of molecular ions was greatly enhanced over protonated ions at fairly specific DBE values as the solvent was switched to toluene. A comparison of Figure 3a and c reveals that the abundance of molecular ions with $\mathrm{DBE} \leq 5$ increased only slightly, whereas the abundance of molecular ions with $\mathrm{DBE} \geq 6$ was significantly greater than that of protonated ions. Figure $3 c$ shows an overall maximum molecular ion abundance at $\mathrm{DBE}=6$ and a local maximum at $\mathrm{DBE}=9$. Note that a DBE difference of three, e.g., the difference between DBE 6 and 9 in Figure 6, can be indicative of an aromatic ring. Compounds with benzothiophene (Figure 6a) and dibenzothiophene (Figure $6 \mathrm{~b}$ ) structures have been previously reported in petroleum fractions [26, 27]. Rudzinski and Rai [28] studied sulfur heterocycles by MS/MS and confirmed the existence of benzothiophene and dibenzothiophene in crude oil. Benzothiophene and dibenzothiophene groups have DBE values of 6 and 9, respectively, which match the observed maxima in the DBE distribution of Figure 3. In addition, both compounds contain thienyl groups and aromatic rings. Creary and coworkers [29] found that thienyl groups had a larger radical-stabilizing effect than did phenyl groups. Therefore, the pattern observed for the enhancement of molecular ions presented in Figure 3 agrees well with the existence of molecules containing benzothiophene and dibenzothiophene groups.

The DBE distributions of $S_{2}$ compounds were also calculated and are presented in Figure 4. Here, the abundance of molecular ions as the solvent was switched to $100 \%$ toluene was especially high at DBE values of 8 and 11. Again, the DBE difference of three is indicative of two structures differing by a single aromatic ring. Based on the same reasoning described above for the $S_{1}$ compounds, these data suggest that the $\mathrm{S}_{2}$ compounds contain a benzothiopene structure with 3 or 4 rings, as shown in Figure $6 \mathrm{c}$ and d, respectively.

The DBE distribution of SO, shown in Figure 5, was unique relative to that of the other compound classes. Protonated ions were abundant, but molecular ions were not observed at DBE values lower than 5, and molecular ions existed with low abundance using the toluene/methanol 50:50 solvent composition (Figure 5a). However, the abundance of molecular ions with DBE values greater than 8 , especially DBE values of 11 and 14, surpassed that of protonated ions as the solvent composition was changed to neat toluene. Saturated cyclic sulfoxide compounds, such as that shown in Figure 6e, have been previously reported in petroleum fractions [30]. In general, saturated cyclic compounds have higher ionization energies than toluene does [12], and it is reasonable to expect that a saturated sulfoxide would not efficiently yield molecular ions via a chargetransfer reaction. In a separate study, Snyder [31] combined petroleum fractionation and high-resolution mass spectrometry and concluded that aromatic compounds with furanyl and thiophenyl functional groups are most likely present in petroleum. Structures with both furanyl and thiophenyl groups are proposed in Figure $6 f$ and g. The proposed structures have DBE values of 11 and 14, which agree well with the observation in Figure 5. In addition, Creary and coworkers [29] reported that furan is a good radical-stabilizing group. Therefore, it is concluded that the SO compounds with DBE values lower than 5 are likely to contain saturated sulfoxide groups, whereas compounds with DBE values higher than 8 most likely contain furanyl and thiophenyl groups.

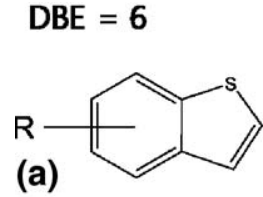

$\mathrm{DBE}=8$

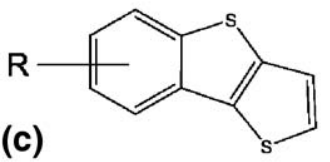

$\mathrm{DBE}=1$

(e)

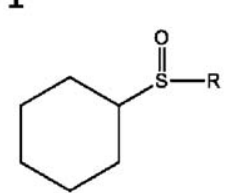

$\mathrm{DBE}=14$

(g)

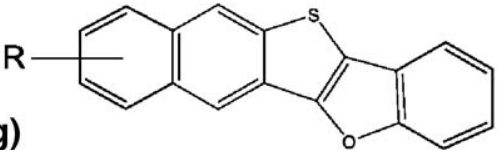

Figure 6. Proposed structures for molecules in petroleum based on the DBE distribution of sulfur-containing compounds. 


\section{Conclusions}

The current study has demonstrated that the formation of molecular ions during positive-ion APCI analyses of petroleum can be enhanced by using neat toluene as the solvent. Comparisons of APCI and APPI data confirmed the findings of Herrera and coworkers [17], which suggested that charge-transfer reaction plays an important role in the generation of molecular ions in positive-ion APCI. It was also demonstrated that the increased abundance of molecular ions could be closely related to the chemical structure of the parent compound. This suggests that monitoring the ratio of molecular to protonated ions using APCI MS with different solvent compositions can provide useful information on the structure of chemical components present in petroleum. More studies with series of hydrocarbon standard compounds will be needed to verify the broader applicability of the current finding. Future efforts will be directed to synthesize standards and test it. In addition, toluene-only solvent has better solubility for petroleum than that of toluene and methanol mixture, which can be responsible for the increased signal abundance. This factor is worthy of further investigation.

\section{Acknowledgments}

The authors thank Drs. Jongshin Yoo, Hyunsik Kim, Myungchul Choi, and Seungyoung Kim for helpful discussions on APCI and APPI analyses, and Mr. Manhoi Hur, Mr. InJoon Yeo, and Ms. Eunsuk Park for their assistance in data interpretation. This work was supported by the Korea Research Foundation (KRF) grant funded by the Korea government (MEST) (No. 2009-0064350).

\section{Appendix A Supplementary Material}

Supplementary material associated with this article may be found in the online version at doi:10.1016/ j.jasms.2009.11.001.

\section{References}

1. Hughey, C. A.; Hendrickson, C. L.; Rodgers, R. P.; Marshall, A. G. Kendrick Mass Defect Spectrum: A Compact Visual Analysis for Ultra-High Resolution Broadband Mass Spectra. Anal. Chem. 2001, 73, 4676-4681.

2. Kim, S.; Rodgers, R. P.; Marshall, A. G. Truly "Exact" Mass: Elemental Composition Can Be Determined Uniquely from Molecular Mass Measurement at Similar to $0.1 \mathrm{mDa}$ Accuracy for Molecules up to Similar to 500 Da. Int. J. Mass Spectrom. 2006, 251, 260-265.

3. Kendrick, E. A Mass Scale Based on $\mathrm{CH}_{2}=14.0000$ for High Resolution Mass Spectrometry of Organic Compounds. Anal. Chem. 1963, 35, $2146-2154$.

4. Kim, S.; Kramer, R. W.; Hatcher, P. G. Graphical Method for Analysis of Ultrahigh-Resolution Broadband Mass Spectra of Natural Organic Matter, the van Krevelen Diagram. Anal. Chem. 2003, 75, 5336-5344.

5. Marshall, A. G.; Rodgers, R. P. Petroleomics: The Next Grand Challenge for Chemical Analysis. Acc. Chem. Res. 2004, 37, 53-59.

6. Klein, G. C.; Kim, S.; Rodgers, R. P.; Marshall, A. G. Mass Spectral Analysis of Asphaltenes. I. Compositional Differences Between Pressure-Drop and Solvent-Drop Asphaltenes Determined by Electrospray Ionization Fourier Transform Ion Cyclotron Resonance Mass Spectrometry. Energy Fuels 2006, 20, 1965-1972.
7. Klein, G. C.; Kim, S.; Rodgers, R. P.; Marshall, A. G.; Yen, A. Mass Spectral Analysis of Asphaltenes. II. Detailed Compositional Comparison of Asphaltenes Deposit to Its Crude Oil Counterpart for Two Geographically Different Crude Oils by ESI FT-ICR MS. Energy Fuels 2006, 20, 1973-1979.

8. Rodgers, R. P.; Schaub, T. M.; Marshall, A. G. Petroleomics: MS Returns to Its Roots. Anal. Chem. 2005, 77, 20A-27A.

9. Marshall, A. G.; Rodgers, R. P. Petroleomics: Chemistry of the Underworld. Proc. Nat. Acad. Sci. U.S.A. 2008, 105, 18090-18095.

10. Schaub, T. M.; Hendrickson, C. L.; Qian, K. N.; Quinn, J. P.; Marshall, A. G. High-Resolution Field Desorption/Ionization Fourier Transform Ion Cyclotron Resonance Mass Analysis of Nonpolar Molecules. Anal. Chem. 2003, 75, 2172-2176.

11. Purcell, J. M.; Hendrickson, C. L.; Rodgers, R. P.; Marshall, A. G. Atmospheric Pressure Photoionization Fourier Transform Ion Cyclotron Resonance Mass Spectrometry for Complex Mixture Analysis. Anal. Chem. 2006, 78, 5906-5912.

12. Constapel, M.; Schellentrager, M.; Schmitz, O. J.; Gab, S.; Brockmann, K. J.; Giese, R.; Benter, T. Atmospheric-Pressure Jaser Ionization: A Novel Ionization Method for Liquid Chromatography/Mass Spectrometry. Rapid Commun. Mass Spectrom. 2005, 19, 326-336.

13. Schmitt-Kopplin, P.; Englmann, M.; Rossello-Mora, R.; Schiewek, R.; Brockmann, K. J.; Benter, T.; Schmitz, O. J. Combining Chip-ESI with APLI (cESILI) as a Multimode Source for Analysis of Complex Mixtures with Ultrahigh-Resolution Mass Spectrometry. Anal. Bioanal. Chem. 2008, 391, 2803-2809.

14. Schrader, W.; Panda, S. K.; Brockmann, K. J.; Benter, T. Characterization of Nonpolar Aromatic Hydrocarbons in Crude Oil Using Atmospheric Pressure Laser Ionization and Fourier Transform Ion Cyclotron Resonance Mass Spectrometry (APLI FT-ICR MS). Analyst 2008, 133, 867869.

15. Hsu, C. S.; Dechert, G. J.; Robbins, W. K.; Fukuda, E. K. Naphthenic Acids in Crude Oils Characterized by Mass Spectrometry. Energy Fuels 2000, 14, 217-223.

16. Roussis, S. G.; Fedora, J. W. Quantitative Determination of Polar and Ionic Compounds in Petroleum Fractions by Atmospheric Pressure Chemical Ionization and Electrospray Ionization Mass Spectrometry. Rapid Commun. Mass Spectrom. 2002, 16, 1295-1303.

17. Herrera, L. C.; Grossert, J. S.; Ramaley, L. Quantitative Aspects of and Ionization Mechanisms in Positive-Ion Atmospheric Pressure Chemical Ionization Mass Spectrometry. J. Am. Soc. Mass Spectrom. 2008, 19, 1926-1941.

18. Horning, E. C.; Horning, M. G.; Carroll, D. I.; Stillwell, R. N. New Picogram Detection System Based on a Mass Spectrometer with an External Ionization Source at Atmospheric Pressure. Anal. Chem. 1973, $45,936-943$.

19. Sunner, J.; Nicoo, G.; Kebarle, P. Factors Determining Relative Sensitivity of Analytes in Positive Mode Atmospheric Pressure Ionization Mass Spectrometry. Anal. Chem. 1988, 60, 1300-1307.

20. Rao, S. S. C.; Fenselau, C. Evaluation of Benzene as a Charge Exchange Reagent. Anal. Chem. 1978, 50, 511-515.

21. Perazzolli, C.; Mancini, I.; Guella, G. Benzene-Assisted AtmosphericPressure Chemical Ionization: A New Liquid Chromatography/Mass Spectrometry Approach to the Analysis of Selected Hydrophobic Compounds. Rapid Commun. Mass Spectrom. 2005, 19, 461-469.

22. Robb, D. B.; Covey, T. R.; Bruins, A. P. Atmospheric Pressure Photoionization: An Ionization Method for Liquid Chromatography-Mass Spectrometry. Anal. Chem. 2000, 72, 3653-3659.

23. Kauppila, T. J.; Kuuranne, T.; Meurer, E. C.; Eberlin, M. N.; Kotiaho, T. Kostiainen, R. Atmospheric Pressure Photoionization Mass Spectrometry. Ionization Mechanism and the Effect of Solvent on the Ionization of Naphthalenes. Anal. Chem. 2002, 74, 5470-5479.

24. Kauppila, T. J.; Kostiainen, R.; Bruins, A. P. Anisole, a New Dopant for Atmospheric Pressure Photoionization Mass Spectrometry of Low Proton Affinity, Low Ionization Energy Vompounds. Rapid Commun. Mass Spectrom. 2004, 18, 808-815.

25. Kolakowski, B. M.; Grossert, J. S.; Ramaley, L. The Importance of Both Charge Exchange and Proton Transfer in the Analysis of Polycyclic Aromatic Compounds Using Atmospheric Pressure Chemical Ionization Mass Spectrometry. J. Am. Soc. Mass Spectrom. 2004, 15, 301-310.

26. Boduszynski, M. M. Composition of Heavy Petroleums. 2. Molecular Characterization. Energy Fuels 1988, 2, 597-613.

27. Chasey, K. L.; Aczel, T. Polycyclic Aromatic. Structure Distributions by High-Resolution Mass Spectrometry. Energy Fuels 1991, 5, 386-394.

28. Rudzinski, W. E.; Rai, V. Detection of Polyaromatic Sulfur Heterocycles in Crude Oil Using Postcolumn Addition of Tropylium and Tandem Mass spectrometry. Energy Fuels 2005, 19, 1611-1618.

29. Creary, X.; Mehrsheikh-Mohammadi, M. E.; McDonald, S. A Comparison of the Radical-Stabilizing Ability of Aromatic Groups. Values for Aromatic Groups. J. Org. Chem. 1989, 54, 2904-2910.

30. Okuno, I.; Latham, D. R.; Haines, W. E. Separation of Sulfoxides from Petroleum Fractions by Cation-Exchange Resin Chromatography. Anal. Chem. 1967, 39, 1830-1833.

31. Snyder, L. R. Petroleum Nitrogen Compounds and Oxygen Compounds. Acc. Chem. Res. 1970, 3, 290-299. 